\title{
Time to transplantation as predictor of hepatocellular recurrence after liver transplantation: a retrospective cohort study
}

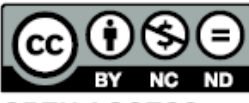

ste articulo esta bajo na licencia de Creative Commons de tipo Reconocimiento - No comecono- Sin obras derivadas 4.0 International

1 Graduate Program in Medicine: Hepatology. Universidade Federal de Ciências da Saúde de Porto Alegre (UFCSPA), Porto Alegre, RS, Brazil.

2 Department of Gastroenterology. Digestive System Surgery, School of Medicine, Hospital das Clínicas,

Universidade de São Paulo (USP), São Paulo, SP, Brasil.

3 Liver Transplantation Group, Santa Casa de Miseri-

córdia de Porto Alegre, Porto Alegre, RS, Brazil.

\section{ORCID ID:}

Santiago Rodríguez.

http:// orcid.org/0000-0001-8610-3622

Lucas Ernani

https://orcid.org/0000-0001-6570-8702

Claudio Augusto Marroni

https://orcid.org/0000-0002-1718-6548

Alfeu de Medeiros Fleck J

https:/ / orcid.org/0000-0002-0424-6919

Ajacio Bandeira de Mello Brandão

https://orcid.org/0000-0001-8411-5654

Received: 14 - may - 2019

Accepted: 24 - jun - 2019

Publish: 1 - november - 2019

Corresponding author: Dr. Santiago Rodríguez V.

E-mail: Santy_rodri03@yahoo.com

Authorship: Santiago Rodriguez conceptualize and designed the data, collected the data, analyzed and interpreted the data, drafted the article, and critically revised the article.

Lucas Ernani collected the data and critically revised the article.

Alfeu de Medeiros Fleck Jr. collected the data and critically revised the article.

Claudio Augusto Marroni collected the data and

critically revised the article.

Ajacio Bandeira de Mello Brandão conceptualized and

designed the data, analyzed and interpreted the data,

drafted the article, and critically revised the article.

Financial disclosure: The authors have no financial relationships relevant to this article to disclose. Santiago Rodriguez is a CAPES (Coordenação de Aperfeiçoamento de Pessoal de Nível Superior) scholarship recipient.

Conflict of Interest: The authors have no conflicts of interest to disclose.

STROBE 2008 CHecklist statement: The authors have real the STROBE 2008 Checklist, and the manuscript was prepared and revised according to the SROBE 2009 Checklist..

Citation: Rodríguez S, Ernani L, Fleck Junior AM, Marroni CA, Brandão ABM Time to transplantation as predictor of hepatocellular recurrence after liver transplantation: a retrospective cohort study. Rev Med Vozandes 2019; 30 (1): 9 - 17.

\begin{abstract}
Hepatocellular recurrence after liver transplantation (LTX) is a major cause of morbidity and mortality. We aimed to investigate the association between waiting time and hepatocellular carcinoma (HCC) recurrence in patients undergoing LTx for HCC. We studied 250 patients who underwent LTx between 2007-2015. Survival and recurrence curves were calculated according to the Kaplan-Meier method and compared by the log-rank test. Univariate hazard ratios for predictors of post-LTx HCC recurrence were determined by Cox proportional hazards regressions. There were no significant differences in recurrence rates when stratified by wait time to transplant. There were also no significant differences in rates of recurrence when the short (< 165 days) and long (> 335 days) wait-time groups were combined, although in this pooled group the 1-year and 5-year cumulative likelihoods of HCC recurrence were higher than in the group with a wait time of 165-334 days. Other predictors of recurrence were microvascular invasion, explant beyond Milan Brazil criteria and tumor diameter $\geq 2.6$. This study found no association between wait time to transplantation and recurrence rates in patients who received LTx for HCC and confirmed that variables associated with tumor biology are associated with HCC recurrence.
\end{abstract}

Keywords: transplant waitlist, hepatocellular carcinoma, liver transplantation, preoperative predictors 
Palabras clave: Lista de espera para trasplante, carcinoma hepatocelular, trasplante de hígado, predictores preoperatorios

\section{Resumen}

Tiempo para el trasplante como predictor de la recurrencia del Carcinoma Hepatocelular después del trasplante hepático: Un estudio de cohorte retrospectivo.

La recurrencia hepatocelular después del trasplante de hígado (TxH) es una de las principales causas de morbi-mortalidad. Nuestro objetivo fue investigar la asociación entre el tiempo de espera y la recurrencia del carcinoma hepatocelular $(\mathrm{CHC})$ en pacientes sometidos a $\mathrm{TxH}$ para CHC. Estudiamos 250 pacientes que se sometieron a TxH entre 2007-2015. Las curvas de supervivencia y recurrencia se calcularon de acuerdo con el método Kaplan-Meier y se compararon mediante logrank test. Las proporciones de riesgo univariados para los predictores de recurrencia posterior al TXH fueron determinadas por las regresiones proporcionales de riesgos de Cox. No hubo diferencias significativas en las tasas de recurrencia cuando se estratificaron por el tiempo de espera para el trasplante. Tampoco hubo diferencias significativas en las tasas de recurrencia cuando se combinaron los grupos de tiempo de espera cortos (< 165 días) y largos (> 335 días), aunque en este ultimo grupo las probabilidades acumuladas de recurrencia de HCC de 1 año y 5 años fueron mayores que en el grupo con un tiempo de espera de 165-334 días. Otros predictores de recurrencia fueron la invasión microvascular, nu cumplir con criterios de Milán Brasil y el diámetro del tumor $\geq 2,6$. Este estudio no encontró ninguna asociación entre el tiempo de espera para trasplante y las tasas de recurrencia en pacientes que recibieron LTx para HCC y confirmó que las variables asociadas con la biología tumoral están asociadas con la recurrencia del HCC.

\section{Introduction}

Liver transplantation (LTX) is the most widely accepted treatment for hepatocellular carcinoma (HCC) in selected patients with cirrhosis ["]. Transplant selection is based on maximization of post-transplant outcome, taking into account such factors as the risk of recurrence after transplantation. This risk is usually estimated using the Milan criteria (MC) ${ }^{[2]}$ : one tumor $\leq 5 \mathrm{~cm}$ or, if multiple tumors are present, a maximum of three nodules $\leq 3 \mathrm{~cm}$, without macroscopic vascular invasion or extrahepatic spread. The 4-year actuarial survival of patients who meet these criteria exceeds $70 \%$, and their 4-year recurrence-free survival rate is estimated to be $83 \%{ }^{[2]}$. Despite these excellent results, using the $\mathrm{MC}$ for $\mathrm{HCC}$ selection does not eliminate the risk of recurrence. Several authors have demonstrated that approximately $8 \%$ to $20 \%$ of patients who meet the criteria will nevertheless develop recurrent disease at a median of 23 to 25 months after LTx ${ }^{[3-5]}$. Conversely, some patients exceeding the MC may have favorable outcomes ${ }^{[6-8]}$, partly because the $M C$ are based solely on preoperative diagnostic imaging.
Microvascular invasion is considered the most accurate predictor of post-LTx tumor recurrence ${ }^{[9]}$. However, this parameter has no practical use, since it can only be detected on histological analysis of the explanted liver.

The Model for End-Stage Liver Disease (MELD) scoring system has been used to prioritize patients for LTx in Brazil since 2006. The model has been validated for predicting 3-month mortality from chronic liver disease in the country ${ }^{[10]}$. However, it is not a good predictor of survival for patients with HCC, because they are at risk of death from tumor progression while their liver function is potentially maintained. In Brazil, to compensate for the expected waitlist dropouts due to cancer progression, patients with $\mathrm{HCC}$ are assigned a minimum score of 20 upon addition to the LTx waiting list. A maximum score of 29 can be attained 6 months after waitlist inclusion. 
It has been postulated that short wait time or rapid LTX would result in the inclusion of tumors with aggressive biologic behavior, at high risk of post-LTx recurrence ${ }^{[11,12]}$. Studies utilizing the United Network Organ Sharing (UNOS) database concluded that a short waiting time is associated with worse survival after LTx for HCC [13, 14]. Samoylova et al. [15] assessed HCC recurrence and found that a wait time of $>4$ months was associated with a $40 \%$ decrease in HCC recurrence. However, other studies, also performed in the United States, did not observe an association between waiting time and outcomes after LTX ${ }^{[16-18]}$.

Recently, a multicenter North American study provided evidence of an association between very short (< 6 months) or very long (> 18 months) wait times and increased risk of HCC recurrence post-LTx ${ }^{[19]}$.

The aim of our study was to evaluate the association between waiting time and $\mathrm{HCC}$ recurrence in patients undergoing LTX for HCC and to compare preoperative demographic and clinical variables and tumor pathological characteristics in a Brazilian cohort of patients.

\section{Patients and methods}

\section{Milan/Brazil criteria}

Since 2006, with the introduction of the MELD for liver allocation in Brazil, candidates with HCC meeting the MC are assigned an exception MELD due to the projected risk of neoplasia progression ${ }^{[20]}$.

These patients are included in the LTx waiting list receiving a minimum score of 20 only for arterial-enhancing lesions with a dimension of at least $2 \mathrm{~cm}$ (one lesion $\geq 2 \mathrm{~cm}$ and $\leq 5 \mathrm{~cm}$; or two or three lesions $\geq 2 \mathrm{~cm}$ and $\leq 3 \mathrm{~cm}$ ). In other words, nodules $<2 \mathrm{~cm}$ are not considered. These modified MC are adopted in Brazil alone, and are thus known as the Milan/Brazil Criteria (MBC). A maximum score of 29 can be attained 6 months after waitlist inclusion.

\section{Cohort selection}

This was a retrospective cohort study. All consecutive adult patients with HCC meeting the MBC listed for LTX between January 2007 and December 2015 at the Liver Transplantation Group of Santa Casa de Misericórdia de Porto Alegre, Brazil, were eligible. Post-LTx recurrence and survival rates were analyzed on June 8, 2017.

The diagnosis of HCC was based on the Barcelona Consensus Statements ${ }^{[21]}$ and American Association for the Study of Liver Diseases Guidelines ${ }^{[22]}$.

Prior to listing for transplantation, extrahepatic disease was excluded with chest computed tomography and bone scintigraphy. Patients with recognized metastases or macrovascular invasion on pretransplant imaging were excluded from LTX.

When waitlist time was predicted to exceed 6 months, patients received locoregional therapy (LRT): percutaneous ethanol injection (PEI), radiofrequency ablation (RFA), or transarterial chemoembolization (TACE), consistent with the number, size, and site of their lesions and considering local availability ${ }^{[23]}$. Those patients with $\mathrm{HCC}$ who did not meet the MBC on pre-LTX imaging were excluded from analyses, unless they were successfully downstaged after locoregional therapies and then fulfilled MBC. Patients with incidentally found $\mathrm{HCC}$ at explant but no pre-LTx evidence of HCC were excluded from the study, as were those with hepatocholangiocarcinoma on explant histology.

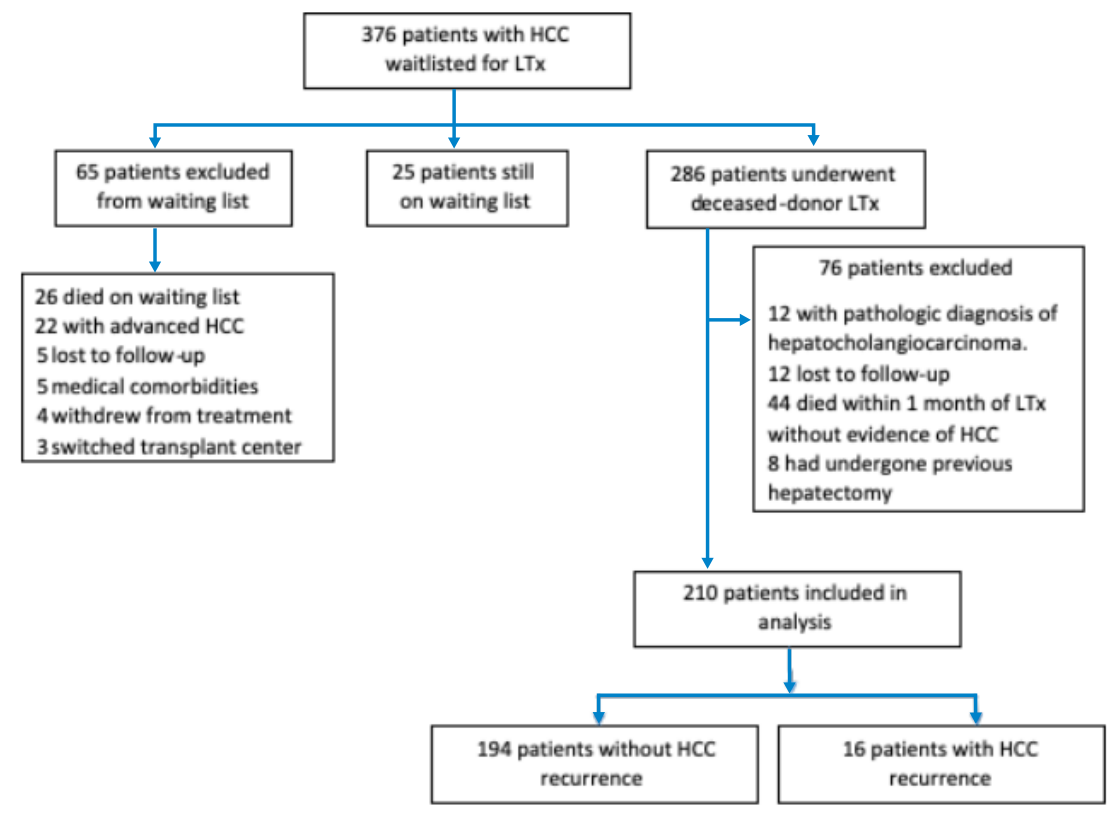

Fig 1. Flow chart of patient enrollment according to HCC non-recurrence or recurrence (January 2007-December 2015) in Southern Brazil 
Table 1 - Demographic, clinical, and pathological parameters of 210 patients with hepatocellular carcinoma (HCC) who underwent liver transplantation (LTX) in Southern Brazil, stratified by time on waiting list since diagnosis.

\begin{tabular}{|c|c|c|c|c|c|c|}
\hline Variable & $\begin{array}{l}\text { Population } \\
(n=210)\end{array}$ & $\begin{array}{l}<165 \text { days } \\
(n=52)\end{array}$ & $\begin{array}{l}165-235 \\
\text { days }(n=52)\end{array}$ & $\begin{array}{l}236-332 \\
\text { days }(n=54)\end{array}$ & $\begin{array}{l}\geq 333 \text { days } \\
(n=52)\end{array}$ & P-value \\
\hline \multicolumn{7}{|l|}{ Patient characteristics } \\
\hline Age (years) $\pm S D$ & $61.5 \pm 7.3$ & $60.4 \pm 7.2$ & $62.7 \pm 7.3$ & $61.0 \pm 7.8$ & $62.0 \pm 6.7$ & 0.413 \\
\hline Male sex, n (\%) & $153(72.9)$ & $39(75.0)$ & $35(67.3)$ & 45 (83.3) & $34(65.4)$ & 0.137 \\
\hline \multicolumn{6}{|c|}{ Etiology of liver disease, $n(\%)$} & 0.591 \\
\hline Hepatitis B & $11(5.2)$ & $3(5.8)$ & $2(3.8)$ & $4(7.4)$ & $2(3.8)$ & \\
\hline Hepatitis C & $172(81.9)$ & $45(86.5)$ & $40(76.9)$ & $45(83.3)$ & $42(80.8)$ & \\
\hline Other & $27(12.9)$ & $4(7.7)$ & $10(19.2)$ & $5(9.3)$ & $8(15.4)$ & \\
\hline \multicolumn{6}{|c|}{ CTP score at transplantation, $\mathrm{n}(\%)$} & 0.085 \\
\hline A & $107(51.2)$ & $23(44.2)$ & $31(59.6)$ & $24(44.4)$ & $29(56.9)$ & \\
\hline B & $81(38.8)$ & $19(36.5)$ & $20(38.5)$ & $25(46.3)$ & $17(33.3)$ & \\
\hline C & $21(10.0)$ & $10(19.2)$ & $1(1.9)$ & $5(9.3)$ & $5(9.8)$ & \\
\hline $\begin{array}{l}\text { AFP (ng/ml) at transplan- } \\
\text { tation }\end{array}$ & $\begin{array}{l}194.80(1.3- \\
6132)\end{array}$ & $\begin{array}{l}84.8(2.5- \\
1528)\end{array}$ & $\begin{array}{l}191.1(1.3- \\
4870)\end{array}$ & $\begin{array}{l}179.9(1.9- \\
3340)\end{array}$ & $\begin{array}{l}324.9(1.8- \\
6123)\end{array}$ & 0.56 \\
\hline \multicolumn{7}{|l|}{ Locoregional treatments } \\
\hline PEl, n (\%) & $45(21.4)$ & $9(17.3)$ & $11(21.2)$ & $13(24.1)$ & $12(23.1)$ & 0.860 \\
\hline TACE, n (\%) & $78(37.1)$ & $14(26.9)$ & $23(44.2)$ & $18(33.3)$ & $23(44.2)$ & 0.179 \\
\hline RFA, n (\%) & $6(2.9)$ & $2(3.8)$ & $1(1.9)$ & $0(0.0)$ & $3(5.8)$ & 0.252 \\
\hline \multicolumn{7}{|l|}{ Explant characteristics } \\
\hline $\begin{array}{l}\text { Milan/Brazil Criteria at } \\
\text { histology, } \mathrm{n}(\%)^{*} \text { a }\end{array}$ & $157(75.1)$ & & & & & 0.919 \\
\hline Fulfilled & $52(24.9)$ & $40(78.4)$ & 38 (73.1) & 41 (75.9) & $38(73.1)$ & \\
\hline \multicolumn{6}{|c|}{ Tumor count at histology, $\mathrm{n}(\%)$ a } & 0.267 \\
\hline 1 & $127(60.8)$ & 32 (62.7) & $35(67.3)$ & $35(64.8)$ & $25(48.1)$ & \\
\hline $2-3$ & $61(29.2)$ & $13(25.5)$ & $14(26.9)$ & $12(22.2)$ & $22(42.3)$ & \\
\hline$>3$ & $21(10.0)$ & $6(11.8)$ & $3(5.8)$ & $7(13.0)$ & $5(9.6)$ & \\
\hline \multicolumn{6}{|c|}{ Tumor diameter at histology, $\mathrm{n}(\%)$ a } & 0.450 \\
\hline$\leq 2 \mathrm{~cm}$ & $70(33.5)$ & $17(33.3)$ & $14(26.9)$ & $24(44.4)$ & $15(28.8)$ & \\
\hline $2.1-5 \mathrm{~cm}$ & $130(62.2)$ & $32(62.7)$ & $34(65.4)$ & 29 (53.7) & $35(67.3)$ & \\
\hline$>5 \mathrm{~cm}$ & $9(4.3)$ & $2(3.9)$ & $4(7.7)$ & $1(1.9)$ & $2(3.8)$ & \\
\hline $\begin{array}{l}\text { Poor differentiation, } n \\
\text { (\%) b }\end{array}$ & $40(22.9)$ & $6(14.6)$ & $12(27.9)$ & $7(14.9)$ & $15(34.1)$ & 0.075 \\
\hline \multicolumn{6}{|l|}{ Necrosis grade, $n(\%)$} & 0.351 \\
\hline Complete & $51(41.8)$ & 11 (39.3) & $12(36.4)$ & $15(51.7)$ & $13(40.6)$ & \\
\hline $\begin{array}{l}\text { Microvascular invasion, } \\
\text { n (\%) a }\end{array}$ & 25 (12.0) & $7(13.7)$ & $5(9.6)$ & $7(13.0)$ & $6(11.5)$ & 0.927 \\
\hline \multicolumn{7}{|c|}{ Data expressed as mean \pm SD or median (interquartile range). } \\
\hline \multicolumn{7}{|c|}{$\begin{array}{l}\text { AFP, alpha-fetoprotein; CTP, Child-Turcotte-Pugh; PEl, percutaneous ethanol injection; RFA, radiofrequency abla- } \\
\text { tion; TACE, transarterial chemoembolization. }\end{array}$} \\
\hline \multicolumn{7}{|c|}{ a Data available for 209 patients. } \\
\hline \multicolumn{7}{|c|}{ b Data available for 175 patients. } \\
\hline * Single node $\geq 2 \mathrm{~cm}$ and $\leq$ & $\leq 5 \mathrm{~cm}$ or & & & & & \\
\hline
\end{tabular}


Waitlist dropout was defined as a patient who was not transplanted and who died or was removed from the waiting list. Patients still waiting on the list as of the date of analysis were censored. Dropout related to HCC disease was defined as tumor progression beyond MBC, metastatic disease, and/or presence of macrovascular invasion on imaging.

For each patient in the group, demographic information, liver function parameters, complete blood count, albumin, and serum alpha-fetoprotein (AFP) were determined on the day before or the day of LTX in all cases.

This study follows the STROBE guidelines for reporting observational studies [24] and was approved by the Institutional Review Board of Santa Casa de Misericórdia de Porto Alegre $N^{0}$ 1.417.586. Informed consent was waived due to the non-interventional design of the study and retrospective nature of data collection. All investigators signed a data use agreement to ensure the ethical and secure use of the data.

\section{Explant tumor characteristics}

An experienced pathologist examined all explanted livers. The post-transplant HCC-related characteristics of interest were: size and number of tumors, degree of differentiation according to the Edmondson criteria ${ }^{[25]}$, macroscopic or microscopic vascular invasion, grade of tumor necrosis, and lymph node involvement. Microvascular invasion was evaluated by analysis of a complete cross-section of the tumor at its greatest diameter or, in tumors $\leq 2.0$ $\mathrm{cm}$, of the entire lesion. Patients with $\mathrm{HCC}$ in the explant were categorized as within $M B C$ or beyond $M B C$.

\section{Waiting time estimation}

Waiting time was defined as the time from diagnosis of $\mathrm{HCC}$ by contrast-enhanced computerized tomography (CT) or magnetic resonance imaging (MRI) to the day of transplant. The day of diagnosis was defined as the date when the lesion was first found on imaging.

\section{Survival and follow-up}

After LTx, all patients were regularly followed up according to local institutional practice, including by liver ultrasound, chest X-ray, and CT or MRI, as needed. Tumor recurrence was defined by clinical, radiological, and/or pathological diagnosis. Overall survival (OS) was defined as time from LTX to death or the latest date of follow-up. Disease-free survival (DFS) was defined as the time from LTx to imaging-

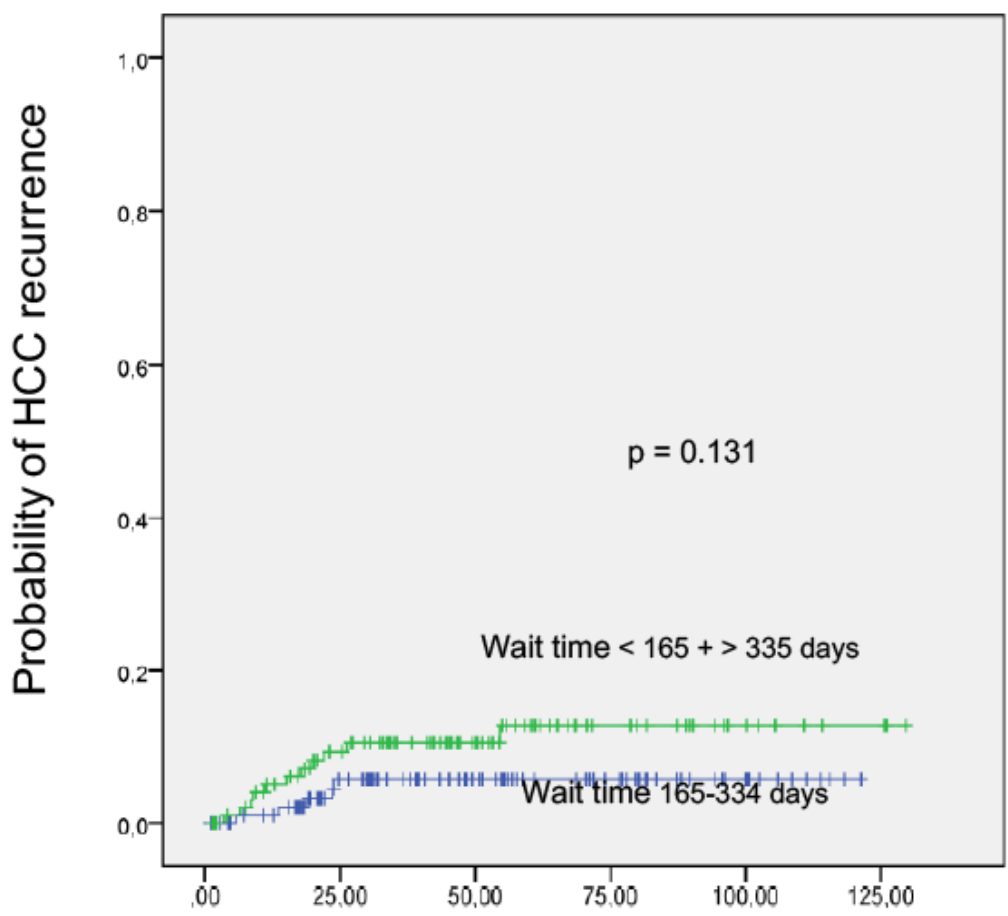

Fig 2. Kaplan-Meier curve of recurrence stratified by waiting time from HCC diagnosis to LT.

\begin{tabular}{|llll|}
\hline Number at risk & 12 mo. & 36 mo. & 60 mo. \\
Wait time $<165+>335$ days & $91(5 \%)$ & $61(10.6 \%)$ & $35(12.8 \%)$ \\
Wait time 165-334 days & $96(1 \%)$ & $60(5.7 \%)$ & $37(5.7 \%)$ \\
\hline
\end{tabular}


Table 2 - Univariate analysis of wait time from HCC diagnosis to LTx as predictor of post-LTx HCC recurrence by Cox proportional hazard regression.

\begin{tabular}{|c|c|c|c|c|c|c|}
\hline $\begin{array}{l}\text { Wait time from } \\
\text { HCC diagnosis to } \\
\text { LTX (days) }\end{array}$ & $\mathrm{n}$ & $\begin{array}{l}\text { Events } \\
\text { (n) }\end{array}$ & $\begin{array}{l}\text { Recurrence rate } \\
(\%)(95 \% \mathrm{Cl})\end{array}$ & Univariate HR & P-value & $\begin{array}{l}-2 \text { log } \\
\text { likelihood }\end{array}$ \\
\hline \multicolumn{7}{|l|}{ Quartiles } \\
\hline$<165$ & 52 & 4 & 7.7 & - & 0.26 & \\
\hline $165-235$ & 52 & 3 & 5.8 & $0.48(0.14-1.65)$ & 0.25 & 160.15 \\
\hline $236-332$ & 54 & 2 & 3.7 & $0.40(0.10-1.56)$ & 0.19 & \\
\hline$\geq 333$ & & 52 & 7 & 13.5 & $0.25(0.53-1.22)$ & 0.09 \\
\hline$<120$ vs & 23 & 3 & 13.0 & $0.61(0.18-2.15)$ & 0.45 & 163.63 \\
\hline$\geq 120$ & 187 & 13 & 7.0 & - & & \\
\hline$<180$ vs & 63 & 5 & 7.9 & $1.05(0.37-3.03)$ & 0.93 & 164.15 \\
\hline$\geq 180$ & 147 & 11 & 7.5 & - & & \\
\hline$<365$ vs & 164 & 10 & 6.1 & $2.39(0.87-6.58)$ & 0.09 & 161.57 \\
\hline$\geq 365$ & 46 & 6 & 13.0 & - & & \\
\hline$<180+>365$ vs & 109 & 11 & 10.1 & $1.2(0.69-5.75)$ & 0.2 & 162.39 \\
\hline $181-365$ & 101 & 5 & 5.0 & - & & \\
\hline$<165+>335$ vs & 104 & 11 & 10.6 & $2.21(0.77-6.37)$ & 0.14 & 161.82 \\
\hline $165-334$ & 106 & 5 & 4.7 & - & & \\
\hline$<160+>365$ vs & 96 & 10 & 10.4 & $1.93(0.70-5.30)$ & 0.20 & 162.48 \\
\hline $161-364$ & 114 & 6 & 5.3 & - & & \\
\hline
\end{tabular}

Table 3 - Univariate analysis of predictors of post-LTx HCC recurrence by Cox proportional hazard regression.

\begin{tabular}{|lll|}
\hline Predictor & Univariate HR $(95 \% \mathrm{Cl})$ & P-value \\
Patient characteristics & $1.01(0.94-1.08)$ & 0.861 \\
Age (per year) & $1.63(0.59-4.48)$ & 0.346 \\
Female sex & $0.91(0.12-6.94)$ & 0.929 \\
HCV vs HBV (ref) etiology & $0.42(0.06-3.16)$ & 0.395 \\
HCV vs nonviral (ref) etiology & $1.00(0.99-1.00)$ & 0.560 \\
AFP (per unit) & $2.55(0.91-7.17)$ & 0.76 \\
AFP $\geq 100$ vs <100 & $0.49(0.11-2.18)$ & 0.351 \\
PEI & $0.77(0.27-2.21)$ & 0.624 \\
TACE & $5.07(1.84-14.00)$ & \\
Explant characteristics & $5.80(2.10-16.01)$ & 0.002 \\
Microvascular invasion & $2.44(1.30-4.58)$ & 0.001 \\
Beyond Milan criteria* & & 0.006 \\
Tumor count (per unit) & - & \\
Tumor diameter & $7.94(1.04-60.68)$ & 0.046 \\
$\leq 2.5 \mathrm{~cm}$ & $27.84(2.51-308.43)$ & 0.007 \\
$2.6-4.9$ cm & $2.07(0.74-5.81)$ & 0.168 \\
$\geq 5$ cm & $6.19(0.78-49.53)$ & 0.086 \\
Poor differentiation & & \\
Partial necrosis & & \\
AFP, alpha-fetoprotein; HBV, hepatitis B virus; HCV, hepatitis C virus; PEl, percutaneous ethanol injection; TACE, \\
transarterial chemoembolization. \\
*Single node $\geq 2$ cm and $\leq 5 \mathrm{~cm}$ or two/three nodes $\geq 2 \mathrm{~cm}$ and $\leq 3 \mathrm{~cm}$.
\end{tabular}


based discovery of HCC recurrence, including intrahepatic recurrence and/or distant metastases. The date of last follow-up for purposes of analysis was June 8, 2017.

\section{Statistical analysis}

Statistical analyses were performed using SPSS 22.0 (IBM Corp., Armonk, NY, USA). Patient characteristics were expressed as mean and standard deviation (SD) for continuous variables and absolute and relative frequencies for categorical variables. Between-group comparisons were performed with Student's t-test or the Mann-Whitney test for quantitative variables. Categorical variables were compared with the chi-square or Fisher tests. Survival and recurrence curves were calculated according to the Kaplan-Meier method and compared by the log-rank test. Univariate hazard ratios (HRs) for predictors of post-LTx HCC recurrence were determined by Cox proportional hazards regressions. This was performed for all know variables prior to transplantation. Multiple cutoffs for waiting time were evaluated using -2 log likelihood ratio (LLR), with lower LR values indicating better model fit. P-values $<0.05$ were considered significant.

\section{Results}

From January 1, 2007, through December 31, 2015, 376 patients with HCC were waitlisted for LTx at the study facility (Figure 1). At the time of our analysis, 25 of those candidates remained on the waiting list, while 65 patients had been removed from the waiting list during the study period. The remaining 286 patients underwent deceased-donor LTx. Overall, 76 patients were excluded from analysis: 44 died within one month of LTx without evidence of HCC recurrence, 12 had a pathologic diagnosis of hepatocholangiocarcinoma, 12 were lost to follow-up, and eight patients underwent prior hepatectomy.
The remaining 210 patients were analyzed.

\section{Demographic characteristics}

The baseline demographic and clinical characteristics of the patients are summarized in Table 1. The mean age was $61.5 \pm 7.3$ years, and $72.9 \%$ were male. The most common etiology of underlying liver disease was hepatitis $C$ virus infection (81.9\%), $51 \%$ of patients were in CTP score category A, and more than onethird of all patients received TACE. At transplantation, the median AFP was 194 (1.3-6123) ng/mL.

\section{Dropout while on the waiting list}

During the study, 65 patients (17.3\%) were removed from the waiting list: 26 died, 22 experienced tumor progression, five were lost to follow-up, five developed medical comorbidities, four withdrew from treatment, and three decided to switch transplant center.

\section{Waiting time and explant fumor characteristics}

In the cohort, 210 patients underwent LTX. The median wait time from HCC diagnosis to LTx was 237 days (211780). Waiting time was stratified into quartiles from $\mathrm{HCC}$ diagnosis until LTX, which were selected as our time points for statistical analysis and to compare shorter and longer vs. intermediate waiting times (Table 1).

These four groups had similar explant tumor characteristics. Most explants met the MBC, and a single nodule with size between $2.0 \mathrm{~cm}$ and 5 $\mathrm{cm}$ was the tumor configuration observed most frequently in all four groups. Complete necrosis with no residual viable tumor because of LRT was seen in $42 \%$ of patients. Among patients with viable tumors in the explant, $15 \%, 28 \%, 15 \%$, and $34 \%$ had poorly

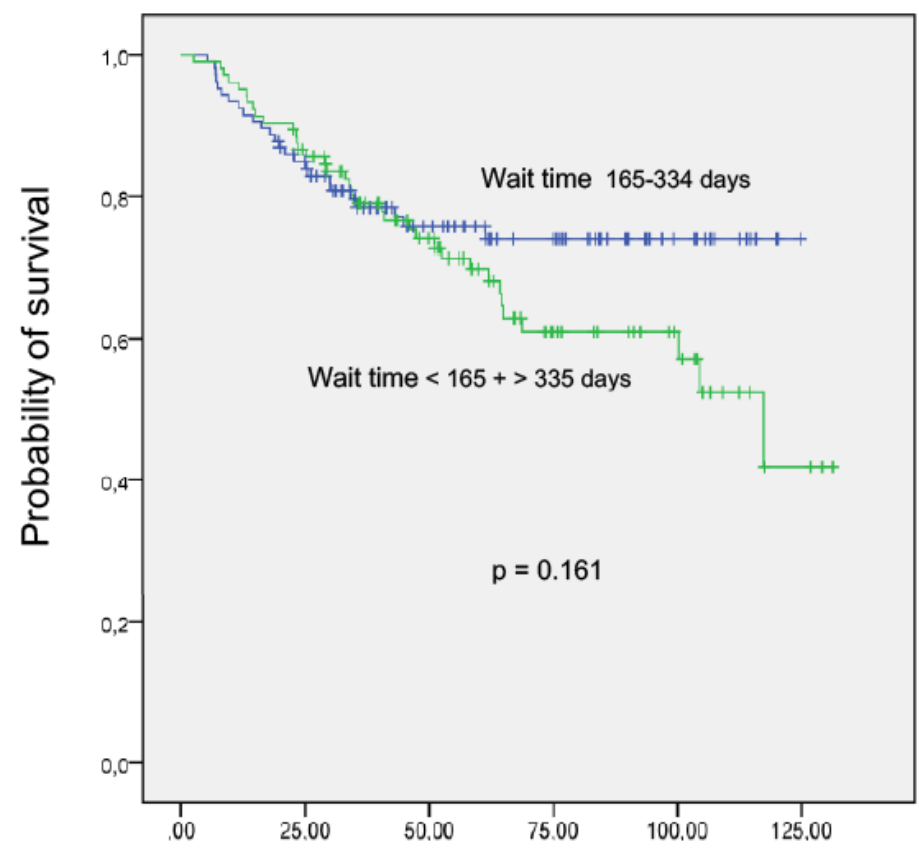

Fig 2. Kaplan-Meier curve of recurrence stratified by waiting time from HCC diagnosis to LT. 
differentiated HCC, respectively (Table 1). The overall incidence of microvascular invasion was similar across the four groups: $14 \%, 10 \%, 13 \%$, and $12 \%$, respectively.

\section{Post-LTx HCC recurrence}

HCC recurrence occurred in $7.6 \%$ of patients at a median of 48.37 months from LTX. Overall post-LTx recurrence rates within 1 and 5 years were $3 \%$ and $9.3 \%$, respectively. There were no significant differences in recurrence rates when stratified by wait time to transplant. Specifically, the recurrence rate for patients waiting $<165$, $165-235$, 236-322, and $\geq 333$ days was $7.7 \%, 5.8 \%, 3.7 \%$, and $13.5 \%$, respectively ( $P=0.313)$. There were also no significant differences in rates of recurrence when the short (< 165 days) and long (> 335 days) wait-time groups were combined ( $n=104)$, although in this pooled group the 1-year and 5-year cumulative likelihoods of HCC recurrence were higher $(5 \%$ and $12 \%$, respectively) than in the group with a wait time of $165-334$ days (1.0\% and $5.7 \%$, respectively) (Figure 2).

\section{Predictors of post-LTx HCC recurrence}

The results of univariate analysis of waiting time as a predictor of HCC recurrence are summarized in Table 2. Waiting time $<165$ or> 335 days presented the best model fit, i.e., the lowest nominal value of -2LL. Other predictors of recurrence were (Table 3): microvascular invasion; explant beyond $\mathrm{MBC}$; tumor count; tumor diameter $\geq 2.6-4.9 \mathrm{~cm}$; and tumor diameter $\geq 5$ $\mathrm{cm}$. Due to the insufficient number of cases, we were unable to construct a predictive model through multivariate analysis.

\section{Post-transplant survival}

Median post-LT follow-up time was 58.7 months, and overall postLT survival was $90.5 \%$ at 1 year and $69.1 \%$ at 5 years. There were no significant differences seen when post-LT survival was stratified by wait time from HCC diagnosis to LT (Figure 3). Specifically, 1-year and 5-year post-LT survival rates were $95.2 \%$ and $69.8 \%$ for waiting time $<165$ days $+>335$ days and $92.5 \%$ and $75.7 \%$ for waiting time between 165 and 334 days (HR 1.44, 95\% Cl 0.86-2.40, $\mathrm{P}=0.161$ ).

\section{Discussion}

The primary objective of this single-center, retrospective cohort study was to assess the impact of wait time as a predictor of HCC recurrence after LTX in the MELD era, in a country which uses a slightly modified version of the MC, the MBC (one lesion $\geq 2 \mathrm{~cm}$ and $\leq 5 \mathrm{~cm}$ or two or three lesions $\geq 2 \mathrm{~cm}$ and $\leq 3 \mathrm{~cm}$ ). In defining wait time, we used the date of HCC diagnosis rather than the date of waitlist inclusion, considering the highly variable time between HCC being diagnosed, the patient been seen at a transplant center, waitlist inclusion, and, eventually, LTx. This definition of waiting time is superior for assessment of the impact of time on HCC recurrence; furthermore, it is universally applicable, as it eliminates confounders inherent to regional transplantation policies and between-center differences in practice regarding LTx in patients with $\mathrm{HCC}$ [18].

In the present study, 1-year and 5-year survival rates after LTX were $95.2 \%$ and $69.8 \%$, respectively. HCC recurred in $7.6 \%$ of patients, a rate similar to that reported by another Brazilian center, in which no difference in recurrence rate was found between patients who met the MC and those who met the $M B C{ }^{[26]}$. Regarding wait time, we found no difference in recurrence rate between LTx recipients in different waiting categories: < 120 vs. > 120 days or < 180 vs. > 180 days or $<365$ vs. $>365$ days between HCC diagnosis and LTX. These results are consistent with previously published studies ${ }^{[16-18]}$. However, when we pooled patients with a waiting time $<165$ and > 335 days and compared them to the group that waited 165-334 days, we found a higher HCC recurrence rate in the former: in patients who were waitlisted for < 165 or $>$ 335 days, the 1-year and 5-year likelihood of recurrence was $5.0 \%$ and $12.8 \%$ respectively, while in those who waited for 165-334 days, these rates were $1 \%$ and $5.7 \%$, respectively. Although there was no significant difference in recurrence rate between the two groups $(P=0.131)$, probably due to the insufficient number of cases, our findings hew close to those reported by Metha et al. [19]: extreme waiting times are associated with higher rates of recurrence as compared to intermediate times. In a multicenter retrospective study $(n=911$; overall recurrence rate 11.2\%), Metha et al. ${ }^{[19]}$ found that patients undergoing LTx for HCC who met the MC and waited < 6 or > 18 months were more likely to experience $\mathrm{HCC}$ recurrence at 1 or 5 years as compared with those who waited 6-18 months. The authors suggested that LTX should be attempted within this window 16 to 18 months after HCC diagnosis), in an attempt to reduce $\mathrm{HCC}$ recurrence rates. The authors suggested that LTx should be attempted within this window (6 to 18 months after HCC diagnosis), in an attempt to reduce HCC recurrence rates. The rationale for avoiding transplantation with short waiting times is to avoid the possibility of transplanting patients with aggressive tumors and higher risk of recurrence ${ }^{[11,12,15]}$ On the other hand, with long waiting times, there is a risk that the biological behavior of HCC will shift; thus, the procedure should be performed before this happens ${ }^{[19]}$. However, the applicability of these conclusions is limited when one considers all of the variables involved in the process since HCC diagnosis: the various criteria for waitlist inclusion, the locoregional therapies available while the patient is on the waiting list, and the number of donors per million population. The impact of waiting time on post-LTx prognosis is especially important within the current context of organ allocation, given mounting evidence of the disparity in LTx access between patients with and those without HCC ${ }^{[27]}$. In an attempt to minimize this issue, in the United States, the UNOS has established a policy that patients with HCC must meet a mandatory waiting period of 6 months before they are considered for exception score status (Organ Procurement and Transplantation Network ${ }^{[28]}$.

Our findings, as recorded elsewhere [11, 12, 15], suggest a significant association of HCC recurrence with microvascular invasion and tumor beyond $\mathrm{MBC}$, both of which are variables identified on explant analysis. However, these 
variables cannot be determined before transplantation, which limits their applicability for prediction of recurrence and estimation of post-LTx survival.

This study has some limitations. First, those inherent to singlecenter, retrospective investigations. Second, the small sample size and low overall recurrence rate, which made it impossible to find statistical significance. Conversely, defining wait time as the time elapsed from diagnosis to LTx allowed us to assess more accurately the impact of time, eliminating confounders that may arise during this period. Additionally, our analyses were restricted to patients who underwent LTx during the Brazilian MELD era, a time during which the criteria for assignment of HCC exception scores remained unchanged.

IEn conclusion, this single-center Brazilian study found no association between wait time to transplantation and recurrence rates in patients who received LTX for HCC. Although we found that patients who wait a relatively short (< 165 days) or long (>335 days) time between HCC diagnosis and LTX experience higher recurrence rates than do those transplanted within an intermediate window of time (165-334 days), there was no significant difference between the two groups. We recommend that further research be conducted with a larger sample to define whether an optimal window for transplantation of patients with HCC exists in Brazil a country that uses a slightly modified version of the Milan criteria. Our study confirmed that variables associated with tumor biology and identifiable only on explant analysis (microvascular invasion and tumor beyond $\mathrm{MBC}$ ) are associated with $\mathrm{HCC}$ recurrence.

\section{Acknowledgements}

The authors thank Ane Micheli Costabeber, Eduardo Schlindwein, Juliano Martini, Ian Leipnitz, Marcos Mucenic, Maria Lúcia Zanotelli, Mario Henrique Meine and Guido Cantisani, members of the Liver Transplantion Group at Santa Casa de Misericórdia de Porto Alegre for their cooperation; Professor Mario Wagner for his assistance with statistical analysis.

\section{Referencias}

1. Diaz-Gonzalez A, Reig M, Bruix J. Treatment of Hepatocellular Carcinoma. Dig Dis 2016; 34: 597-602.

2. Mazzaferro V, Regalia E, Doci R, et al. Liver transplantation for the treatment of small hepatocellular carcinomas in patients with cirrhosis. $\mathrm{N}$ Engl J Med 1996; 334: 693-9.

3. Zimmerman MA, Ghobrial RM, Tong MJ, et al. Recurrence of hepatocellular carcinoma following liver transplantation: a review of preoperative and postoperative prognostic indicators. Arch Surg 2008; 143: 182-8; discussion 188.

4. Sharma $P$, Welch $K$, Hussain $H$, et al. Incidence and risk factors of hepatocellular carcinoma recurrence after liver transplantation in the MELD era. Dig Dis Sci 2012; 57: 806-12.

5. Clavien PA, Lesurtel M, Bossuyt PM, et al. Recommendations for liver transplantation for hepatocellular carcinoma: an internationa consensus conference report. Lancet Oncol 2012; 13: e11-22.

6. Yao FY, Ferrell L, Bass NM, et al. Liver transplantation for hepatocellular carcinoma: expansion of the fumor size limits does not adversely impact survival. Hepatology 2001; 33: 1394-403.

7. Herrero JI, Sangro B, Quiroga J, et al. Influence of tumor characteristics on the outcome of liver transplantation among patients with liver ver transplantation among patients with liver Cirrhosis and hepato

8. Bonadio I, Colle I, Geerts A, et al. Liver transplantation for hepatocellular carcinoma comparing the Milan, UCSF, and Asan criteria: longterm follow-up of a Western single institutiona experience. Clin Transplant 2015; 29: 425-33.

9. Jonas S, Bechstein WO, Steinmuller T, et al. Vas cular invasion and histopathologic grading determine outcome after liver transplantation for hepatocellular carcinoma in cirrhosis. Hepatology 2001; 33: 1080-6.

10. Brandao A, Fuchs SC, Gleisner AL, Marroni C, Zanotelli ML, Cantisani G. Model for the end-stage liver disease and death prediction in a cohort of Brazilian patients on the waiting list for liver transplantation. Clin Transplant 2008; 22: 651-6.

11. Roberts JP, Venook A, Kerlan R, Yao F. Hepatocellular carcinoma: Ablate and wait versus rapid transplantation. Liver Transpl 2010; 16: 925-9.

12. Kulik LM, Fisher RA, Rodrigo DR, et al. Outcomes of living and deceased donor liver transplant recipients with hepatocellular carcinoma: results of the A2ALL cohort. Am J Transplant 2012 12: 2997-3007.

13. Halazun KJ, Patzer RE, Rana AA, et al. Standing the test of time: outcomes of a decade of prioritizing patients with hepatocellular carcinoma, results of the UNOS natural geographic experiment. Hepatology 2014; 60: 1957-62.

14. Schlansky B, Chen Y, Scott DL, Austin D, Naugler WE. Waiting time predicts survival after liver transplantation for hepatocellular carcinoma: a cohort study using the United Network for Organ Sharing registry. Liver Transpl 2014; 20: 1045-56.

15. Samoylova ML, Dodge JL, Yao FY, Roberts JP. Time to transplantation as a predictor of he patocellular carcinoma recurrence after liver transplantation. Liver Transpl 2014; 20: 937-44.

16. Chao SD, Roberts JP, Farr M, Yao FY. Short waitlist time does not adversely impact outcome following liver transplantation for hepatocellula carcinoma. Am J Transplant 2007; 7: 1594-600.

17. Bittermann T, Hoteit MA, Abt PL, Forde KA, Goldberg $\mathrm{D}$. Waiting time and explant pathology in transplant recipients with hepatocellular carcinoma: a novel study using national data. Am J Transplant 2014; 14: 1657-63.

18. Palmer WC, Lee D, Burns J, et al. Liver Transplantation for Hepatocellular Carcinoma: Impact of Wait Time at a Single Center. Ann Hepato 2017; 16: 402-411.

19. Mehta N, Heimbach J, Lee D, et al. Wait Time of Less Than 6 and Greater Than 18 Months Predicts Hepatocellular Carcinoma Recurrence After Liver Transplantation: Proposing a Wait
Time "Sweet Spot". Transplantation 2017; 101: 2071-2078.

20. Goldberg D, French B, Abt P, Feng S, Cameron AM. Increasing disparity in waitlist mortality rates with increased model for end-stage liver disease scores for candidates with hepatocellular carcinoma versus candidates without hepatocellular carcinoma. Liver Transpl 2012; 18: 434-43.

21. Bruix J, Sherman M, Llovet JM, et al. Clinical management of hepatocellular carcinoma. Conclusions of the Barcelona-2000 EASL conference. European Association for the Study of the Liver. J Hepatol 2001; 35: 421-30.

22. Bruix J, Sherman M, Practice Guidelines Committee AAftSoLD. Management of hepatocellular carcinoma. Hepatology 2005; 42: 120836.

23. Jarnagin W, Chapman WC, Curley S, et al. Surgical treatment of hepatocellular carcinoma: expert consensus statement. HPB (Oxford) 2010; 12: 302-10.

24. von Elm E, Altman DG, Egger $M$, et al. The Strengthening the Reporting of Observational Studies in Epidemiology (STROBE) statement: guidelines for reporting observational studies. J Clin Epidemiol 2008; 61:344-9.

25. Edmondson HA, Steiner PE. Primary carcinoma of the liver: a study of 100 cases among 48,900 necropsies. Cancer 1954; 7: 462-503.

26. Sa GP, Vicentine FP, Salzedas-Netto AA, et al. Liver Transplantation for Carcinoma Hepatocellular in Sao Paulo: 414 Cases by the Milan/ Brazil Criteria. Arq Bras Cir Dig 2016; 29: 240-245.

27. Northup PG, Intagliata NM, Shah NL, Pelletier SJ, Berg CL, Argo CK. Excess mortality on the liver transplant waiting list: unintended policy consequences and Model for End-Stage Liver Disease (MELD) inflation. Hepatology 2015; 61: 285-91

28. United States. Department of Health \& Human Services [Internet]. Organ Procurement and Transplantation Network [cited 2017 Nov 28]. Available from: https://optn.transplant.hrsa.gov/ 